\title{
CSU Pathway Courses During COVID-19: A Multi-Faceted Support Strategy for Online Engagement
}

\author{
Amita Krautloher \\ Educational Designer \\ Charles Sturt University
}

\begin{abstract}
In March 2020, Charles Sturt University (CSU) launched two new pathway courses: the Diploma of General Studies (DGS) and the CSU Pathway course. These courses are offered at five regional campuses, along with an online offering. This particular cohort of students lack the skills and confidence necessary to engage with university-level study. With the advent of COVID-19, the challenge was to transition the five on-campus cohorts to a fully online mode of delivery within a few weeks. This task was further complicated as a number of teaching staff on the program were new to CSU, with little to no experience teaching explicitly online.
\end{abstract}

This paper showcases the student-centric strategies adopted to transition on-campus students to online delivery. A summary will also be provided of the successes of this approach (to date), particularly in terms of retention and progression, along with the lessons learnt as part of the process.

\section{Keywords}

COVID-19, pandemic, transition to online study, CSU, pathways, foundation studies, student-centric strategies, student experience, teaching and learning strategies, online learning, multi-campus cohorts, enabling courses, supporting students online

\section{Introduction}

At the start of 2020, Charles Sturt University (CSU) launched two new pathway courses: a revised Diploma of General Studies (DGS) and a new CSU Pathway course. Apart from dealing with the challenges of rolling out new courses, the course team had to deal with the pandemic within the first weeks of the first offering of the courses. This article presents how a three-person course management team dealt with the challenges of transitioning the geographically diverse on-campus students to online study during COVID-19.

\section{Background}

The pathway courses are offered at five campus locations: Albury, Bathurst, Dubbo, Port Macquarie, and Wagga Wagga, as well as online. Students receive guaranteed entry into most of the degrees at CSU on successful completion of these courses.

The students enrolled in these courses are typically recent school leavers who may not have received a sufficient ATAR to be accepted into the degree of their choice or non-school leavers returning to education after a long break. These students may not have had a positive schooling experience. The younger students are often not independent learners and lack the skills and confidence to undertake university study; they tend to prefer the on-campus experience and require high levels of support.

\section{Impact of COVID-19 and key issues arising}

When the situation with COVID-19 worsened, the on-campus classes were required to transition to online in under three weeks. At that stage, the multi-campus cohorts had enrolments in excess of 550 students, with more than 30 academic staff teaching on the program and a management team of three people, the Program Coordinator, the Program Development Officer, and the Program Support Officer. To prepare for the transition, the university decided to bring the mid-session break forward by two weeks. 


\section{Objectives of the transition strategy}

The transition strategy revolved around the student profile. The aim of the transition plan was to minimise disruption to the students' lives, as moving to online study was already a significant disruption.

The main objectives of the transition were as follows:

1. managing the learning content,

2. preparing staff for transition,

3. preparing students for transition,

4. transition to the virtual campus and ensuring that the new normal worked well, and

5. monitoring engagement during and post transition.

\section{Challenge 1 - Managing learning materials}

Merging the subject sites in the Learning Management System (LMS) was a key decision in managing the learning materials and ensuring equity and consistency across cohorts. The learning materials were decontextualised to suit all the students irrespective of their mode of study, whether on campus or online.

Subject Convenors had ownership of the subject sites for uploading resources and posting announcements. Subject Coordinators (SCs) at each campus focussed on supporting the students. Working from the same subject sites, academics were able to support each other more easily, and students had the freedom to access resources posted by any of the SCs, including the lecture recordings.

\section{Challenge 2 - Preparing staff for transition}

The students studying on-campus are generally young school leavers who require significant support to develop their skills and confidence. It was considered important to maintain the same teaching hours, as there was a concern that any reduction in the contact time may have resulted in a high number of enrolment withdrawals. On campus students had 2x2 hour lecture tutorials scheduled for each subject, each week, so there was no change to teaching hours in the online delivery transition, which also meant staff teaching contracts were not affected.

A number of academics were new to CSU and were not completely familiar with CSU systems, so they had to master a range of new tools to cope with the transition of curriculum delivery.

Professional development sessions were offered by the university to all staff to upskill them with the core learning technology tools: Adobe Connect, Zoom (lecture delivery), Panopto (lecture capture), and Blackboard (LMS). Best practice exemplar subject sites were showcased to help academics identify strategies to engage students in the online space.

The most significant challenge for many academics was to re-think and pivot their delivery strategies away from teaching face-to-face on campus to teaching online. To support this switch, they were provided with guidelines on dos and don'ts in online classes as well as ways to bring variety into their sessions to enhance student engagement. Academics were also trained to complete subject-related administration tasks, such as collecting attendance records and posting lecture recordings online.

\section{Challenge 3 - Preparing students for transition}

The courses were offered at five campus locations, with two or three classes at each campus location; the core strategy was to have small class sizes to allow lecturers to effectively engage with their students and support them in their transition to university study. Students chose class groups based 
on the suitability of the timetable for their needs at the start of the session. It was understood that students had already organised their work and life around their study timetable, and, for some, any further disruption would have potentially meant disengagement and withdrawal from the courses. Therefore, it was decided to retain the same timetable in the online space, and an Adobe Connect classroom was set up for each group at each campus, with students accessing the same online classroom for all their subjects.

To prepare students for the transition, even before the mid-session break, some academics posted video guidelines on how it would work, and some academics used the last few days on campus to explain the transition to students and address their concerns face-to-face. Many academics took the approach of "we are in this together, and we will get through this together" which helped to build students' confidence and desire to persevere.

A multi-tiered support network was set up at the start of the session which worked very well during the pandemic. Students were guided as to who to approach for what type of query.

- Subject related issues $\rightarrow$ the relevant academic

- Non-subject related queries $\rightarrow$ Campus Coordinator

- Academics and Campus Coordinators, as the first point of contact, assessed students' issues and, if required, directed them to appropriate support services.

- Course/subject administration related queries $\rightarrow$ Campus Coordinator who would then direct them to appropriate person within the program management team (either the Program Support Officer or the Program Coordinator)

- University systems related issues $\rightarrow$ Student Central.

\section{Challenge 4 - Transition to the virtual campus}

Once students returned after the break to the virtual campus, the primary focus was to ensure that they were orientated to navigate the new normal. Most of the academics invested the first and second weeks in guiding students and addressing their concerns about studying online and in adjusting their delivery strategies for the online space:

- To help students settle in their new mode of study, they were taught the etiquettes of an online classroom, for example, how to enter the online classroom, testing their microphone and speakers, how to ask a question, guidance on acceptable comments, waiting for their turn to interact, and being respectful of others' views.

- Academics used the subject landing page to post announcements and information to support students.

- The Program Development Officer shadowed the first few sessions of each subject to ensure that they were running smoothly and to support the academics if necessary.

- Peer-to-peer engagement was promoted synchronously via the Adobe Connect or Zoom classrooms and asynchronously via Padlets and the class discussion board. Students were encouraged to continue supporting each other in the online space and to further develop the bonds they had formed in the on-campus classrooms.

- Some Campus Coordinators set-up their own Facebook (FB) groups to support their students. There was also a FB mentoring group set-up for pathway students that was independent of the course organisers and the academics. It operated as a platform for students to connect with their peers and voice any concerns that they may have had with their subjects and courses. 


\section{Challenge 5 - Monitoring student engagement during and post transition}

For two weeks after the mid-session break, the academics re-established communication with the students who did not attend the online classes. They assessed students' issues and, when appropriate to do so, recommended various support services to assist students.

It was essential to ensure that the early engagement did not decline as the session progressed, so analytics were used to assess student engagement. Any disengagement was assessed through the lens of subject resources and teaching issues rather than just students' personal learning challenges.

Simple strategies to increase engagement with the subject site included a gradual introduction of topics, so not all the topics were initially available. This encouraged students to revisit the subject site to review and download new topic resources. Academics were also encouraged and supported to enhance interactivity in their sessions.

Reports detailing students who were potentially 'at risk' of disengagement were provided to SCs. The SCs then reached out to these students via email and telephone and offered support in one-to-one consultations to help resolve subject related issues, offer extensions to assessment due dates, and recommended support services as required such as literacy and numeracy support, and offered introductions to disability services, career services, counselling services, and financial support as needed. Campus Coordinators and the Program Support Officer also reached out to students to offer support. If students chose to withdraw, including post-census date, these requests were processed swiftly.

\section{Progress update}

The formal retention, progression and attrition rates in the courses will be finalised and released approximately at the start of April 2021.

In the interim, the subject based figures have been used to calculate the retention and completion rates as follows:

- Student retention in the subjects was approximately 90\%; it was calculated on enrolments at census date minus the withdrawals during the session.

- Average completion with a passing grade in the subjects was $80 \%$.

- The early enrolment figures show that about $60 \%$ of the CSU Pathway course students have enrolled in an undergraduate degree.

- About 30\% of CSU Pathway course students started their undergraduate degree in session 2, 2020. This is important because many of the popular degree programs do not have a mid-year intake. Some of the degree programs this cohort enrolled into were Bachelor of Education Studies, Bachelor of Social Science (Psychology), Bachelor of Social Work, Bachelor of Science and Bachelor of Criminal Justice.

- About $45 \%$ of the Diploma of General Studies students enrolled to start a degree in Session $1,2021$.

\section{Student feedback}

A short survey was conducted to gain feedback on students' experience of the transition (37 responses out of 120 surveyed). The issues raised are comparable with the TEQSA findings regarding the strategies implemented during the pandemic across the sector (Martin, 2020).

- In response to the question that asked about their feelings about the transition to online study, about $35 \%$ of students found it stressful and difficult. This aligns with TEQSA findings that the disaffected students range from 33 to 50\% (Martin, 2020), 27\% of students settled quickly into online study, $16 \%$ of students did not feel any impact from transitioning to online study, 
and about $22 \%$ of students have come to prefer this mode of study, which was an unexpected and interesting revelation.

- In response to the question whether the lecturers and CSU staff were approachable and understood the challenges students were experiencing, $88 \%$ responded yes, and $12 \%$ were neutral, with no negative responses.

- Campus Coordinator (CC) positions were created to be the local contact for students at their campus. In response to the question whether students were aware of their $\mathrm{CC}, 82 \%$ of students said yes, and $18 \%$ said no.

- The next question was to verify whether students contacted their CC and received any support. This was an open-ended question where students responded variously as follows: they contacted their $\mathrm{CC}$ to find support services; they felt motivated by and received emotional support from the $\mathrm{CC}$; and that the $\mathrm{CC}$ helped rationalise difficult situations, offered reassurances, as well as offering multiple options to address their challenges, which helped students feel understood and supported.

- In response to the question whether they felt supported in transitioning to online learning, overall, students concurred that their lecturers were very helpful and supportive. Students also demonstrated empathy and understanding of the challenges experienced by the lecturers during the pandemic which is similar to what was seen across the sector (Martin, 2020). This arguably resulted from the close bonds the lecturers had formed with their students and the open and transparent way in which they approached the challenges.

- Improvement suggestions included developing a better sense of community amongst students in the online space which is similar to what has been highlighted in the TEQSA report (Martin, 2020). Some students missed the social connections that arose from face-to-face contact with other students and staff, and the ability to ask for help face-to-face. There was also a suggestion that there be a shift away from the one-way lecture - slide show presentations in online classes.

\section{Lessons learned and areas for improvement}

The conclusions drawn about the lessons learned were arrived at in consultation with Subject Convenors for each subject in the program, Subject Coordinators, Campus Coordinators, the Facebook Mentoring Group Coordinator, and student feedback. The lessons learned have been divided into strategies which were applied during the pandemic that have become accepted practice in the subsequent offerings of the courses, and areas for improvement.

Key learnings informing teaching and learning practice

- Merging subject sites was an important strategy: apart from managing the learning materials, it helped build stronger teaching teams and has paved the way for team teaching in the future. It also enhanced the flexibility of access to resources for students. This approach has now been promoted to the rest of the university.

- It was essential to maintain identity of individual cohorts within the merged subject sites so that the SCs did not feel a loss of control and students did not feel lost within the larger pool of students.

- Using the 'Smartview' functionality in Blackboard was very helpful to manage large cohorts in the merged subject sites. It simplified retrieving student work, returning marked assessments and updating large cohorts within grade centre.

- Maintaining the same timetable and contact hours was crucial for retention, which has been identified as an important issue in the TEQSA report (Martin, 2020). 
- Continuing to engage students asynchronously using Padlet and discussion boards.

- Enhancing familiarity with the support services and boosting students' confidence to seek assistance by inviting support services representatives to online classes.

Areas for improvement

- Academics need to continue to upskill in online teaching to enhance the student experience.

- Although attempts were made to encourage peer-to-peer interaction, this is an area that requires a concerted strategic effort to avoid students feeling isolated.

- This was also a very challenging time for academic staff. Looking after their wellbeing through regular virtual catch-ups would be an important strategy should a similar situation arise in the future.

- A more proactive pastoral care approach from the Campus Coordinators would be essential to look after the wellbeing of students and help address their issues.

\section{Conclusion}

In conclusion, the transition to online study as a result of COVID-19 pandemic was a significant success as demonstrated by the high retention and completions figures, and the student feedback. The success of the student-centric strategies adopted during the pandemic are aligned with the TEQSA findings on similar measures taken during this period. These findings have informed the teaching and learning approaches that will be implemented in subsequent offerings of the courses. Although there were challenges, staff were able to successfully address them, enabling the majority of students to complete their course and move on to their chosen undergraduate degree. The valuable lessons learned has helped to prepare the Charles Sturt Pathways team to cope with similar challenges in the future. 


\section{References}

Martin, L. (2020). Foundations for good practice: The student experience of online learning in Australian Higher Education during the COVID-19 pandemic. Australian Government Tertiary Education Quality and Standards Agency. Retrieved from https://www.teqsa.gov.au/latest-news/publications/foundations-good-practice-studentexperience-online-learning-australian

The author may be contacted

akrautloher@csu.edu.au

Please cite this paper as:

Krautloher, A (2021). CSU Pathway Courses during COVID-19: A multi-faceted support strategy for online engagement. Journal of the Australian and New Zealand Student Services Association, 29(1), 101-107. https://doi.org.10.30688/janzssa.2021.1.06 